DOI: $10.4274 /$ jarem.galenos.2021.02486

J Acad Res Med 2021;11(3):249-53

\title{
Retrospective Analysis of the Perinatal Outcomes in Preeclampsia and Eclampsia in a Tertiary Care Center
}

\author{
(1) Çağlar Helvacıoğlu1, (1) Güneş Topçu1, (1) Gözde Konak1, (1) İbrahim Kale1, (ㄷ) Cem Yalçınkaya2, (1) Ayşegül Özel3 \\ ${ }^{1}$ University of Health Sciences Turkey, Ümraniye Training and Research Hospital, Clinic of Obstetrics and Gynecology, İstanbul, Turkey \\ 2University of Health Sciences Turkey, Ümraniye Training and Research Hospital, Clinic of Gynecologic Oncology, İstanbul, Turkey \\ ${ }^{3}$ University of Health Sciences Turkey, Ümraniye Training and Research Hospital, Clinic of Perinatology, İstanbul, Turkey
}

Cite this article as: Helvacıoğlu Ç, Topçu G, Konak G, Kale I, Yalçınkaya C, Özel A. Retrospective Analysis of the Perinatal Outcomes in Preeclampsia and Eclampsia in a Tertiary Care Center. J Acad Res Med 2021;11(3):249-53

\begin{abstract}
Objective: Preeclampsia is a multisystemic disease of unknown etiology that increases maternal and fetal mortality and morbidity. Early diagnosis and appropriate management of the disease are essential to prevent adverse outcomes. This study aims to report the pregnancy and perinatal outcomes of preeclampsia and eclampsia cases.

Methods: A total of 510 patients diagnosed with preeclampsia or eclampsia were followed up in our hospital between 2015 and 2020 , and they were evaluated retrospectively. Demographic characteristics, laboratory values, maternal, and fetal results of these patients were used for the comparative analysis.

Results: The mean age of the patients, gestational weeks at birth, platelet counts, and birth weight of the newborn were 28 years, 37 weeks, 194,000 cells $/ \mathrm{mm}^{3}$, and $2960 \mathrm{~g}$, respectively. Among the newborns, 34.4\% required intensive care. Of the pregnant patients, $48.7 \%$ delivered vaginally, while $51.3 \%$ delivered by cesarean section. Placental abruption was observed in $2.9 \%$, eclampsia in $2 \%$, and HELLP syndrome was noted in $1 \%$ patients.

Conclusion: Preeclampsia is one of the hypertensive diseases of pregnancy that can negatively affect the life of the mother and the baby. Therefore, high-risk pregnant women should be examined in the early weeks of pregnancy. The necessity of referral to tertiary centers is vital for optimal management.

Keywords: Pregnancy, preeclampsia, eclampsia, perinatal outcomes
\end{abstract}

ORCID IDs of the authors: Ç.H. 0000-0002-6247-2383; G.T. 0000-0003-4784-6356; G.K. 0000-0002-2008-7241; I.K. 0000-0001-7802-7199; C.Y. 00000003-1579-7238; A.Ö. 0000-0002-0283-1049. 


\section{Introduction}

Preeclampsia is a pregnancy-specific disease characterized by high blood pressure and proteinuria. It increases morbidity and mortality, and its etiology is still unknown. The incidence in nulliparous pregnant women varies from $2 \%$ to $7 \%$ (1). Hypertensive disorders in pregnancy are responsible for $14 \%$ of maternal mortality globally (2). Severe preeclampsia is seen more frequently in patients with risk factors such as preeclampsia history, first pregnancy, multiple pregnancies, presence of chronic hypertension and diabetes mellitus, and history of thrombophilia $(1,3)$. Blood pressure measurement during pregnancy, especially during the second trimester, is important for preeclampsia diagnosis. In preeclampsia, visual and prodromal symptoms such as headache and epigastric pain may accompany hypertension. Preeclampsia findings can also be seen in cases where systemic findings (liver dysfunction, renal failure, cerebral and visual symptoms, pulmonary edema, hemolysis, and the presence of thrombocytopenia) coexist with hypertension (4). Eclamptic crisis or hemolysis, elevated liver enzymes, and decreased platelet count (HELLP syndrome) may develop as a complication of preeclampsia. In preeclampsia, regular controls, early diagnosis and blood pressure regulation, eclampsia prophylaxis, referral to a tertiary center, and timely decisions on the mode of delivery can reduce fetomaternal mortality and morbidity (5).

This study aimed to evaluate the changes in biochemical parameters and report prenatal and maternal outcomes among patients diagnosed with preeclampsia or eclampsia and delivered in our clinic, as well as to share our experiences in a tertiary care center.

\section{METHODS}

İstanbul University of Health Sciences Ümraniye Training and Research Hospital Clinical Research Ethics Committee of approved the study (decision no: 386, date: 03.12.2020). The medical records of 510 patients diagnosed with preeclampsia and delivered in the Ümraniye Training and Research Hospital between 2015 and 2020 were retrospectively analyzed. Information was obtained from the computerized files of the patients. Patient consent was not obtained because the study was conducted retrospectively. Patients who were followed up in our clinic and whose files could not be accessed, cases whose births occurred elsewhere or whose babies were transferred to another center, and multiple pregnancies were excluded from the study.

The diagnostic evaluation of these patients was made according to the American College of Obstetricians and Gynecologist preeclampsia diagnostic criteria as follows: systolic pressure $\geq 140 \mathrm{mmHg}$ and diastolic pressure $\geq 90 \mathrm{mmHg}$ measured at least four hours apart in pregnant women over 20 weeks of gestation, a protein amount of $300 \mathrm{mg}$ in 24-hour urine or a urine protein/ creatinine ratio of 0.3 , or if these measurements cannot be performed, +1 protein in dipstick urine (1).
Proteinuria in 24-hour urine and dipstick urine values were not considered since the diagnosis was made using the protein/ creatinine ratio in spot urine in our clinic.

The gestational age of the cases was calculated according to the last menstrual period (LMP). In cases of unknown LMP, early fetal biometric measurements were taken into account. Fetal mortality was defined as fetuses older than 22 weeks of gestation without a heartbeat. Babies born before 37 weeks of gestation were considered premature.

\section{Statistical Analysis}

Mean, standard deviation, median, range, frequency, and ratio were used for descriptive statistics. Data were entered into Microsoft Excel and were analyzed with the Statistical Package of the Social Sciences Inc., Chicago, IL, USA version 27.0.

\section{RESULTS}

The mean ages of the enrolled patients, gestational age at delivery, systolic blood pressure and diastolic blood pressures at diagnosis, spot urine protein/creatinine ratio, platelet count, serum glutamic oxaloacetic transaminase, and serum glutamic pyruvic transaminase values were 28 years ( $14-48$ years), 37 weeks (22-42 weeks), $130 \mathrm{mmHg}(100-220 \mathrm{mmHg}), 80 \mathrm{mmHg}(54-140$ $\mathrm{mmHg}), \quad 0.6(0.3-26.5), \quad 194.000 / \mathrm{mm}^{3}\left(16.000-391.000 / \mathrm{mm}^{3}\right), 12$ IU/L (6-530 IU/L) and 23 IU/L (8-431 IU / L), respectively. Essential demographic data, blood pressure measurements, and laboratory parameters of patients are shown in Table 1.

The mean infant birth weight was $2690 \mathrm{~g}$ (340-5165 g), and 48.7\% $(n=248)$ and $51.3 \%(n=261)$ of the patients delivered vaginally and by cesarean section, respectively. Eclampsia was observed in $2 \%$

\begin{tabular}{|c|c|c|c|c|}
\hline \multirow[b]{2}{*}{ Age } & \multicolumn{3}{|c|}{$\min -\max$} & \multirow{2}{*}{$\begin{array}{l}\text { Median } \\
28.0\end{array}$} \\
\hline & 14.0 & - & 48.0 & \\
\hline Gravida & 1.00 & - & 17.00 & 2.00 \\
\hline Parity & 0.00 & - & 6.00 & 1.00 \\
\hline $\begin{array}{l}\text { Week of gestation at } \\
\text { diagnosis }\end{array}$ & 22.5 & - & 42.0 & 37.4 \\
\hline $\mathrm{SBP}(\mathrm{mmHg})$ & 100.0 & - & 220.0 & 130.0 \\
\hline $\mathrm{DBP}(\mathrm{mmHg})$ & 54.0 & - & 140.0 & 80.0 \\
\hline $\begin{array}{l}\text { Spot urine protein/ } \\
\text { creatinine ratio }\end{array}$ & 0.3 & - & 26.5 & 0.6 \\
\hline Creatinine (mg/dL) & 0.4 & - & 5.2 & 0.6 \\
\hline Hemoglobin ( $g / d L)$ & 8.4 & - & 17.7 & 11.7 \\
\hline Platelet (cell/m³) & 16.0 & - & 391.0 & 194.0 \\
\hline SGOT (IU/L) & 6.0 & - & 530.0 & 12.0 \\
\hline SGPT (IU/L) & 8.0 & - & 431.0 & 23.0 \\
\hline LDH (IU/L) & 129.0 & - & 2148.0 & 331.0 \\
\hline
\end{tabular}


$(n=10)$ of the patients, HELLP syndrome in 1\% $(n=5)$, placental abruption in $2.9 \%(n=15)$, and intrauterine death in $1.8 \%(n=9)$. Neonatal intensive care unit (NICU) admissions were required in $34.4 \%(n=175)$ of cases, mainly due to prematurity $(14.9 \%, n=76)$, hyperbilirubinemia $(11.2 \%, n=57)$, respiratory distress syndrome, sepsis, transient tachypnea of the newborn, pneumonia, hypoglycemia, and others. Labor characteristics, fetomaternal outcomes, and NICU admission indications are presented in Table 2. The risk factors for preeclampsia are shown in Table 3.

\section{DISCUSSION}

Preeclampsia, which occurs in the second half of pregnancy, is a serious health problem in developing countries because it is associated with high maternal and fetal morbidity and mortality rates $(6,7)$. In the management of preeclamptic cases, early detection, controlling blood pressure, loading $\mathrm{MgSO}_{4^{\prime}}$ and rapid delivery in severe cases are very important. In our clinic, we follow the ISHPP guidelines for diagnosing and managing

\section{Table 2. Labor characteristics, fetomaternal outcomes, and NICU admission indications}

\begin{tabular}{|c|c|c|c|c|c|c|c|}
\hline \multirow{2}{*}{\multicolumn{2}{|c|}{ Newborn's birth weight (g) }} & \multicolumn{3}{|c|}{$\min -\max$} & \multirow{2}{*}{$\begin{array}{l}\text { Median } \\
2960.0\end{array}$} & \multirow[t]{2}{*}{$n$} & \multirow[t]{2}{*}{$\%$} \\
\hline & & 340.0 & - & 5165.0 & & & \\
\hline APGAR 1 & & 0.0 & - & 7.0 & 7.0 & & \\
\hline APGAR 5 & & 0.0 & - & 8.0 & 8.0 & & \\
\hline \multirow{2}{*}{ Type of delivery } & Vaginal Delivery & & & & & 248 & $48.7 \%$ \\
\hline & Cesarean & & & & & 261 & $51.3 \%$ \\
\hline Eclampsia & $(+)$ & & & & & 10 & $2.0 \%$ \\
\hline HELLP syndrome & $(+)$ & & & & & 5 & $1.0 \%$ \\
\hline Abruptio & $(+)$ & & & & & 15 & $2.9 \%$ \\
\hline Intrauterin death & $(+)$ & & & & & 9 & $1.8 \%$ \\
\hline NICU admission & $(+)$ & & & & & 175 & $34.4 \%$ \\
\hline \multicolumn{8}{|c|}{ NICU Admission Indications } \\
\hline Prematurity & & & & & & 76 & $14.9 \%$ \\
\hline Hyperbilirubinemia & & & & & & 57 & $11.2 \%$ \\
\hline RDS & & & & & & 16 & $3.1 \%$ \\
\hline Sepsis & & & & & & 15 & $2.9 \%$ \\
\hline TTN & & & & & & 43 & $8.4 \%$ \\
\hline Pneumonia & & & & & & 12 & $2.4 \%$ \\
\hline Hypoglycemia & & & & & & 2 & $0.4 \%$ \\
\hline Other & & & & & & 49 & $9.6 \%$ \\
\hline
\end{tabular}

\section{Table 3. Risk factors for preeclampsia}

\begin{tabular}{|l|l|l|}
\hline & Adjusted OR & $95 \% \mathbf{C l}$ \\
\hline Age $>40$ years & 1.54 & $1.1-2.3$ \\
\hline $\mathrm{BMI}>25\left(\mathrm{~kg} / \mathrm{m}^{2}\right)$ & 2.8 & $1.8-4.7$ \\
\hline Nulliparity & 1.72 & $1.26-2.45$ \\
\hline Smoking & 1.20 & $0.7-2.20$ \\
\hline Chronic hypertension & 2.80 & $1.8-4.20$ \\
\hline Assisted reproductive techniques & 1.56 & $1.1-2.20$ \\
\hline Prior preeclampsia & 3.5 & $2.2-5.7$ \\
\hline BMI: body mass index, OR: odds ratio, Cl: confidence interval & & \\
\hline
\end{tabular}


hypertensive patients (8). Preeclampsia can occur alone or concurrently with other underlying risk factors and superimposed on chronic hypertension (9). The previously reported risk factors of preeclampsia, including maternal age, nulliparity, chronic hypertension, diabetes, multiple gestations, ethnicity, use of assisted reproductive techniques, prior preeclampsia history, and obesity, were confirmed as the independent predictors of preeclampsia. Although advanced maternal age is one of the risk factors of preeclampsia, it can also be observed in adolescent pregnancies (10). In this study, the mean age of the enrolled women was 28 years (range: 14-48 years). A study by Dağdeviren et al. (11) reported the mean age of 35 years in their population. They had never observed preeclampsia in patients younger than 17 years of age. Our rates of adolescent pregnancy were higher; thus, our mean age was younger.

Many complications such as maternal HELLP syndrome, abruption, disseminated intravascular coagulation, renal failure, cerebral hemorrhage, pulmonary edema, fetal intrauterine growth retardation, and intrauterine death may be observed $(9,12,13)$. Eclampsia developed in $2 \%$ of our patient group, HELLP syndrome in $1 \%$, and placental abruption in $2.9 \%$. The patients who developed eclampsia $(n=10)$ continued to receive $\mathrm{MgSO}_{4}$ for 48 hours in the postpartum period. No eclamptic seizures were observed in the postpartum period. In 2020, Lai et al. (5) reported similar adverse maternal outcome rates. The definitive treatment of preeclampsia is terminating the pregnancy through delivery $(2,14)$. When adverse events develop, the type of birth becomes, and their timing is crucial. Preeclampsia alone is not an indication for cesarean section. Overall, $48.7 \%$ of the patients in our study had a vaginal delivery, and $51.3 \%$ delivered through cesarean section. Başol et al. (15) and Dağdeviren et al. (11) also reported similar birth rates. However, the cesarean rates in our region and approach to the delivery methods affected these rates. Three out of the five patients who developed HELLP syndrome were followed up in the intensive care unit, while the other two were followed up with close monitoring. These patients were treated using $\mathrm{MgSO}_{4}$, corticosteroids, antihypertensives, blood products, and supportive treatments.

In a study by Susilo et al. (16) determined that preeclampsia is an independent risk factor for a low $1^{\text {st }}$ minute Apgar score. Asseffa and Demissie (17) reported a NICU admission rate of $11.1 \%$ among newborns of preeclamptic/eclamptic mothers, and AduBonsaffoh et al. (18) reported a high rate of NICU admission in preeclampsia compared with other hypertensives disorders in pregnancy. Our NICU admission rate was 34\%. Preterm delivery is one of the most critical complications of hypertensive disorders in pregnancy, and preterm babies are more likely to be admitted to the NICU than term infants (12). In our study, the most common reason for hospitalization in the NICU was prematurity ( $n=76,14.9 \%$ ). Our stillbirth rate was $1.8 \%$, while those reported in the literature varied between $0.26 \%$ and $6 \%$. In the review by Nicolaides, stillbirth rate was decreased to $0.26 \%$ with aspirin use (19). Low molecular weight heparin, folic acid, enoxaparin, PETN, yoga, and vitamin $\mathrm{D}$ alone or combined with calcium can be used to prevent preeclampsia and reduce fetomaternal complications (20).

\section{Study Limitations}

The limitations of our study include its retrospective nature, the fact that we present only descriptive data that we did not distinguish between primary and recurrent cesarean rates, and the lack of distinction between early and late-onset as well as mild and severe disease.

\section{CONCLUSION}

Hypertensive disorders in pregnancy are a significant health problem associated with preventable adverse maternal and fetal outcomes. Therefore, high-risk populations should be screened early and referred to a tertiary center when necessary. In addition, adverse perinatal outcomes could be decreased in experienced and well-equipped clinics. Finally, we require an international program to increase society's awareness toward the adverse perinatal outcomes of hypertensive disorders in pregnancy.

Ethics Committee Approval: İstanbul University of Health Sciences Ümraniye Training and Research Hospital Clinical Research Ethics Committee of approved the study (decision no: 386, date: 03.12.2020).

Informed Consent: Patient consent was not obtained because the study was conducted retrospectively.

Peer-review: Externally and internally peer-reviewed.

Author Contributions: Surgical and Medical Practices - C.Y.; Concept I.K., A.Ö.; Design - Ç.H.; Data Collection and/or Processing - G.T.; Analysis and/or Interpretation - A.Ö.; Literature Search - G.T., G.K.; Writing - Ç.H., G.T.

Conflict of Interest: The authors have no conflict of interest to declare.

Financial Disclosure: The authors declared that this study has received no financial support.

\section{REFERENCES}

1. Gestational Hypertension and Preeclampsia: ACOG Practice Bulletin, Number 222. Obstet Gynecol 2020; 135: e237-60. doi: 10.1097/ AOG.0000000000003891..

2. Say L, Chou D, Gemmill A, Tunçalp Ö, Moller AB, Daniels J, et al. Global causes of maternal death: a WHO systematic analysis. Lancet Glob Health 2014; 2: e323-33. doi: 10.1016/S2214-109X(14)70227-X.

3. Ye L, Shi MD, Zhang YP, Zhang JS, Zhu CR, Zhou R. Risk factors and pregnancy outcomes associated with retinopathy in patients presenting with severe preeclampsia: A retrospective cohort study. Medicine (Baltimore) 2020; 99: e19349. doi: 10.1097/MD.0000000000019349.

4. Hypertension in pregnancy. Report of the American College of Obstetricians and Gynecologists' Task Force on hypertension in pregnancy. Obstet Gynecol 2013; 122: 1122-31.

5. Lai J, Syngelaki A, Nicolaides KH, von Dadelszen P, Magee LA. Impact of new definitions of preeclampsia at term on identification of adverse maternal and perinatal outcomes. Am J Obstet Gynecol 2021; 224: 518. e1-518.e11. doi: 10.1016/j.ajog.2020.11.004.

6. Yılmaz Baran Ş, Alemdaroğlu S, Durdağ GD, Yetkinel S, Yüksel Şimşek $\mathrm{S}$, Kalaycı $\mathrm{H}$, et al. Reappraisal of the relationship between 24-hour proteinuria and preeclampsia in terms of the maternal and perinatal outcomes. Hypertens Pregnancy 2020; 39: 82-8.

7. Macedo TCC, Montagna E, Trevisan CM, Zaia V, de Oliveira R, Barbosa CP, et al. Prevalence of preeclampsia and eclampsia in adolescent pregnancy: a systematic review and meta-analysis of 291,247 adolescents worldwide since 1969. Eur J Obstet Gynecol Reprod Biol 2020; 248: 177-86. 
8. Brown MA, Magee LA, Kenny LC, Karumanchi SA, McCarthy FP, Saito S, et al; International Society for the Study of Hypertension in Pregnancy (ISSHP). The hypertensive disorders of pregnancy: ISSHP classification, diagnosis \& management recommendations for international practice. Pregnancy Hypertens 2018; 13: 291-310.

9. Naruse K, Shigemi D, Hashiguchi M, Imamura M, Yasunaga H, Arai T; Advanced Life Support in Obstetrics (ALSO)-Japan Research Group. Placental abruption in each hypertensive disorders of pregnancy phenotype: a retrospective cohort study using a national inpatient database in Japan. Hypertens Res 2021; 44: 232-8.

10. Skråstad RB, Hov GG, Blaas HG, Romundstad PR, Salvesen KÅ. A prospective study of screening for hypertensive disorders of pregnancy at 11-13 weeks in a Scandinavian population. Acta Obstet Gynecol Scand 2014; 93: 1238-47.

11. Dağdeviren $H$, Çankaya $A$, Cengiz $H$, Tombul $T$, Kanawati $A$, Süzen Çaypınar S, et al. Maternal and neonatal outcomes of women with preeclampsia and eclampsia at a tertiary care center. Haseki Tıp Bülteni 2015; 53: 143-6.

12. Roberge S, Nicolaides KH, Demers S, Villa P, Bujold E. Prevention of perinatal death and adverse perinatal outcome using low-dose aspirin: a meta-analysis. Ultrasound Obstet Gynecol 2013; 41: 491-9.

13. Wójtowicz A, Zembala-Szczerba M, Babczyk D, Kolodziejczyk-Pietruszka M, Lewaczynska O, Huras H. Early- and late-onset preeclampsia: a comprehensive cohort study of laboratory and clinical findings according to the new ISHHP criteria. Int J Hypertens 2019; 2019: 4108271. doi: 10.1155/2019/4108271.
14. Tlaye KG, Endalfer ML, Kassaw MW, Gebremedhin MM, Aynalem YA. Preeclampsia management modalities and perinatal death: a retrospective study in Woldia general hospital. BMC Pregnancy Childbirth 2020; 20: 205

15. Başol G, Uzun ND, Uzun F, Kale A, Terzi H. Retrospective analysis of the preeclampsia cases delivered in our clinic between 2013 and 2017. Perinatal Journal 2018; 26: 135-40.

16. Susilo SA, Pratiwi KN, Fattah ANA, et al. Determinants of low APGAR score among preeclamptic deliveries in Cipto Mangunkusumo Hospital: a retrospective cohort study in 2014. Med J Indones 2015; 24: 183-9.

17. Asseffa NA, Demissie BW. Perinatal outcomes of hypertensive disorders in pregnancy at a referral hospital, Southern Ethiopia. PLoS One. 2019; 14: e0213240. doi: 10.1371/journal.pone.0213240.

18. Adu-Bonsaffoh K, Obed SA, Seffah JD. Maternal outcomes of hypertensive disorders in pregnancy at Korle Bu Teaching Hospital, Ghana. Int J Gynaecol Obstet 2014; 127: 238-42.

19. Rolnik DL, Nicolaides KH, Poon LC. Prevention of preeclampsia with aspirin. Am J Obstet Gynecol 2020: S0002-9378: 30873-5. doi: 10.1016/j. ajog.2020.08.045. Epub ahead of print.

20. Rahnemaei FA, Fashami MA, Abdi F, Abbasi M. Factors effective in the prevention of preeclampsia: a systematic review. Taiwan J Obstet Gynecol 2020; 59: 173-82. 